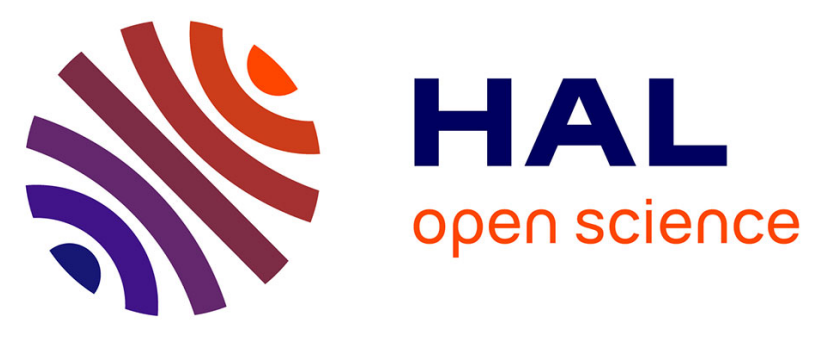

\title{
Influence of the Casting Microstructure upon the Tensile Behaviour in A319 Al-Si Alloy Investigated by X-Ray Tomography and Digital Volume Correlation
}

Long Wang, Nathalie Limodin, Ahmed El Bartali, Julien Réthoré, Jean-françois Witz, Rian Seghir, Eric Charkaluk, Jean-yves Buffiere

\section{To cite this version:}

Long Wang, Nathalie Limodin, Ahmed El Bartali, Julien Réthoré, Jean-françois Witz, et al.. Influence of the Casting Microstructure upon the Tensile Behaviour in A319 Al-Si Alloy Investigated by X-Ray Tomography and Digital Volume Correlation. Second International Congress on 3D Materials Science, 2014, Annecy, France. pp.73-78, 10.1007/978-3-319-48123-4_12 . hal-01668787

\section{HAL Id: hal-01668787 https://hal.science/hal-01668787}

Submitted on 15 Jul 2021

HAL is a multi-disciplinary open access archive for the deposit and dissemination of scientific research documents, whether they are published or not. The documents may come from teaching and research institutions in France or abroad, or from public or private research centers.
L'archive ouverte pluridisciplinaire HAL, est destinée au dépôt et à la diffusion de documents scientifiques de niveau recherche, publiés ou non, émanant des établissements d'enseignement et de recherche français ou étrangers, des laboratoires publics ou privés. 


\title{
INFLUENCE OF THE CASTING MICROSTRUCTURE UPON THE TENSILE BEHAVIOUR IN A319 Al-Si ALLOY INVESTIGATED BY X- RAY TOMOGRAPHY AND DIGITAL VOLUME CORRELATION
}

\author{
Long Wang ${ }^{1}$, Nathalie Limodin ${ }^{1}$, Ahmed El Bartali ${ }^{1}$, Julien Rethore ${ }^{2}$, Jean-François \\ Witz $^{1}$, Rian Seghir ${ }^{1}$, Eric Charkaluk ${ }^{1}$, Jean-Yves Buffiere ${ }^{3}$ \\ ${ }^{1}$ Laboratoire de Mécanique de Lille (LML), CNRS UMR 8107; Cité Scientifique; Villeneuve \\ d'Ascq, Nord, 59650, France \\ ${ }^{2}$ Laboratoire de Mécanique des Contacts et des Structures (LaMCoS), CNRS UMR 5259; 18-20, \\ rue des Sciences; Villeurbanne, Rhône, 69621, France \\ ${ }^{3}$ Laboratoire Matériaux, Ingénierie et Sciences (MATEIS), INSA-Lyon, CNRS UMR 5510; 20 \\ Av. Albert Einstein; Villeurbanne, Rhône, 69621, France
}

Keywords: Aluminum-silicon alloys, Digital Volume Correlation, X-ray tomography

\begin{abstract}
Aluminum alloy automotive parts produced by the Lost Foam Casting (LFC) process have coarser microstructure and porosity defects than parts produced with conventional casting processes at faster cooling rates. This coarse microstructure has a major influence on the fatigue properties and crack initiation. In order to study its influence upon the mechanical behaviour, an experimental protocol has been set up using X-ray tomography and 3D Digital Volume Correlation (DVC). The present work focuses on the use of this protocol to study the influence of the casting microstructure upon the tensile behaviour. The $3 \mathrm{D}$ cracks were observed to initiate at large pores and microshrinkage cavities and then to propagate along the hard inclusions towards the free surface when cracks originate from a subsurface pore. The validated experimental protocol is presently applied to in-situ fatigue tests realized with synchrotron tomography and a newly developed DVC platform in order to analyze the damage micromechanisms of this alloy subjected to low cycle fatigue test.
\end{abstract}

\section{Introduction}

In the automotive industry, the conventional die casting process is progressively being replaced by the Lost Foam Casting (LFC) process for the purpose of geometry optimization, cost reduction and consumption control. However, aluminum alloy automotive parts produced by the LFC process have a coarser microstructure and more porosity defects than parts produced with conventional casting processes at faster cooling rates. This microstructure has a major influence on the fatigue properties. Above a critical size, pores [1] play a decisive role by providing preferential crack initiation sites. However, an influence of oxides [2], iron-based intermetallics [3] and Si particles [4] is also observed. The cracks can initiate at defects present in bulk of the material and, in low cycle fatigue, the failure often results from multicracking rather than from a single crack. In order to study the influence of this microstructure upon the mechanical behaviour in bulk, an experimental protocol, which allows following the cracks initiation and propagation in 3D, has been set up using X-ray tomography and Digital Volume Correlation 
(DVC). The present work focuses on the use of this protocol to study the influence of the casting microstructure upon the tensile behaviour.

\section{Experimental procedure}

The alloy used in this study is an A319 Aluminum Silicon alloy (Table I), which is used for manufacturing of cylinder heads and is casted by a LFC process. Small specimens (Figure 1 (a)) were extracted from automotive cylinder heads provided by PSA Company by electro discharge machining. The screening of specimens was realized prior to the tensile test using a laboratory computed X-ray tomography system V-Tomex (MATEIS laboratory, Lyon, France) in the fast scan mode, i.e. the scan lasts about 5 minutes, at a $4.5 \mu \mathrm{m}$ voxel size; these medium resolution images allow revealing the size and shape of the large pores inside the specimens gauge length rapidly. The chosen specimens have no large defects near the shoulders while they have defects with a size compatible with the specimen cross-section in the gauge length.

Table I: Chemical composition of LFC A319 Al-Si alloy (mass percentage)

\begin{tabular}{|r|c|c|c|c|c|c|c|c|c|c|c|c|}
\hline $\mathrm{Al}$ & $\mathrm{Si} \%$ & $\mathrm{Mn} \%$ & $\mathrm{Fe} \%$ & $\mathrm{Mg} \%$ & $\mathrm{Cu} \%$ & $\mathrm{Zn} \%$ & $\mathrm{Ti} \%$ & $\mathrm{Ni} \%$ & $\mathrm{~V} \%$ & $\mathrm{Zr} \%$ & $\mathrm{Sr}(\mathrm{ppm})$ & $\mathrm{P}(\mathrm{ppm})$ \\
\hline bal. & 7.18 & 0.15 & 0.43 & 0.32 & 3.17 & 0.19 & 0.05 & 0.010 & 0.020 & 0.006 & 0.002 & 0.010 \\
\hline
\end{tabular}

The selected specimens were then polished on both faces up to a $1 / 4 \mu \mathrm{m}$ surface finish. The matrix, i.e. the material without pores, of these specimens was segmented from the X-ray tomography $3 \mathrm{D}$ image and a geometric model with a volumetric tetrahedral grid was created using Avizo software. The model was then used for finite element simulation using Abaqus software in order to predict the most strained region under tensile loading and to focus the subsequent in-situ observation by high resolution X-ray tomography on this small volume.

The in-situ tensile test was performed at the MATEIS laboratory. A $80 \mathrm{kV}$ acceleration voltage was selected to enable for at least $10 \%$ transmission of incoming X-ray beam. The specimens were placed on the rotating stage in the tomography chamber between the X-ray source and the detector. A set of 900 radiographies was recorded while the specimen was rotating over $360^{\circ}$ along its vertical axis. An acquisition time per image of $500 \mathrm{~ms}$ yields a scan duration of $45 \mathrm{~min}$. An in-situ test rig [5] was installed in the tomography chamber in order to load the specimen (Figure 1 (b)). First, the specimen was scanned under minimum load with a voxel size of $1.7 \mu \mathrm{m}$ and $1.695 \mu \mathrm{m}$ separately in order to later assess the uncertainty of DVC [6]. The obtained image at $1.695 \mu \mathrm{m}$ was further used as a reference for DVC and for the $3 \mathrm{D}$ characterization of the ironbased intermetallics and $\mathrm{Al}_{2} \mathrm{Cu}$ phase. Then the specimen was loaded step by step until fracture and a scan was performed at each step with a $1.695 \mu \mathrm{m}$ voxel size. Loading procedure is illustrated in Figure 1(c); the stresses for the 6 steps correspond to 147, 165, 176, 188, 192 and, $198 \mathrm{MPa}$ respectively.

Besides, a larger sample of the same material was scanned with a voxel size of $3 \mu \mathrm{m}$ in order to characterize the pores distribution in a much larger, hence more representative, volume, i.e. 70 $\mathrm{mm}^{3}$ vs. $8.2 \mathrm{~mm}^{3}$ for the studied tensile specimen. 


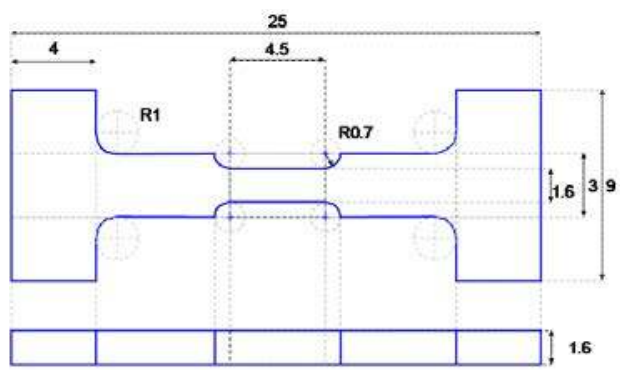

(a)

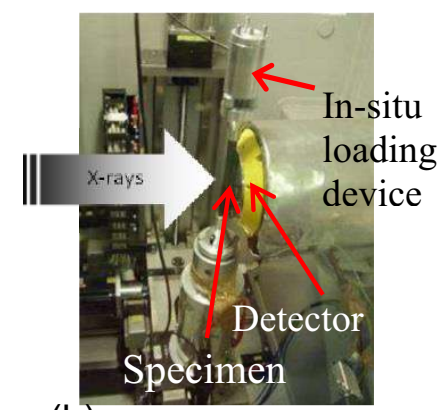

(b)

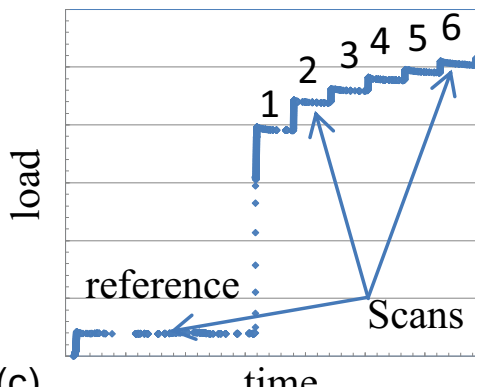

(c)

time

Figure 1. In-situ tensile test with: (a) specimen geometry (dimensions in $\mathrm{mm}$ ), (b) in-situ test rig inside the tomography chamber and (c) the loading procedure

The images processing and pores analysis were performed with Avizo software. Feret diameter, which is the distance between the two farthest points on the surface of an object, was used to characterize the size of pores. The granulometry analysis, which allows calculating the thickness distribution of interconnected phases such as iron intermetallics and $\mathrm{Al}_{2} \mathrm{Cu}$ phase, was performed with the "Analysis_3D" plugin in Fiji software [7].

The displacement field was measured with the DVC technique [8], which is an extension of the well-developed Digital Image Correlation (DIC) method, using the Mechanical Image Correlation (MIC3D) algorithm developed by J. Réthoré. The numerous and finely dispersed microstructural features inside the material, i.e. iron intermetallics and $\mathrm{Al}_{2} \mathrm{Cu}$ phase, were successfully used as natural markers.

\section{Results and discussion}

\section{$\underline{3.13 \mathrm{D} \text { characterization of specimens }}$}

An example of 3D rendering of pores in the bulk of a selected specimen is shown in Figure 2(a). Numerous large pores were found in the central part of the specimen and some of them having sharp shape produce large stress concentration. The volume fraction porosity in the studied tensile specimen is $0.88 \%$, which is close to that measured in a larger volume of the material $(1.17 \%)$. Distributions of pores in the small tensile specimen and in a larger volume are shown in Figure 2(b): the green (resp. red) curve and histogram stand for the pores distributions in the tensile specimen (resp. studied material) with a voxel size of $4.5 \mu \mathrm{m}$ (resp. $3 \mu \mathrm{m}$ ) in number and volume frequency, respectively. While the first peak in the number distribution corresponds to small rounded gas pores, the peak in the volume distribution corresponds to large microshrinkage cavities, which are fewer in number but do represent most of the pores volume fraction. The small difference between tensile test and the material for the first peak in the number distribution may be caused both by the different resolutions used, which controls the detectability of small pores, and by the scattering in microstructure. Figure 2(b) shows that the selected tensile specimen is representative of the studied cast material in terms of the size distribution of small pores and most importantly of large pores, which are believed to play the most important part in damage initiation, all the more so as they present sharp edges, which induce stress concentration. Consequently, all the in-situ observations during mechanical tests were performed with a higher 
resolution but in a smaller volume, which was focused on a zone of interest where cracks were more likely to initiate, i.e. in the neighbourhood of large pores.

The $3 \mathrm{D}$ rendering of iron intermetallics and eutectic $\mathrm{Al}_{2} \mathrm{Cu}$ phase in the studied alloy (Figure 3 (a) and (b)) explains why only a granulometry analysis could be used to characterize the thickness distribution of these highly interconnected phases (Figure 3(d)). As shown in Figure 3(c), although the average thickness of the interdendritic phases is almost the same, the maximum thickness of iron intermetallics is much larger. However, the maximum size of pores being more than 10 times larger than that of iron intermetallics, pores were assumed to be the most critical defects and the present analysis will focus on their influence upon tensile damage initiation.

(a)
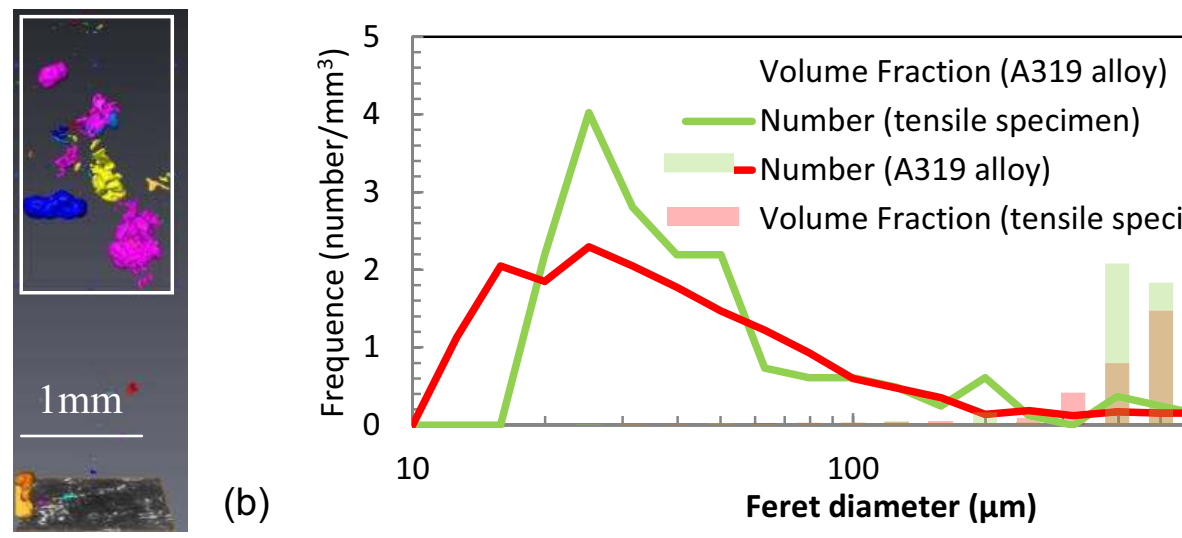

Number (tensile specimen)

- Number (A319 alloy)

Volume Fraction (tensile specimen)

Figure 2. (a) 3D rendering of pores in the tensile specimen (Zone of interest is delimited by a white box) and (b) size distributions of pores for tensile and large specimens
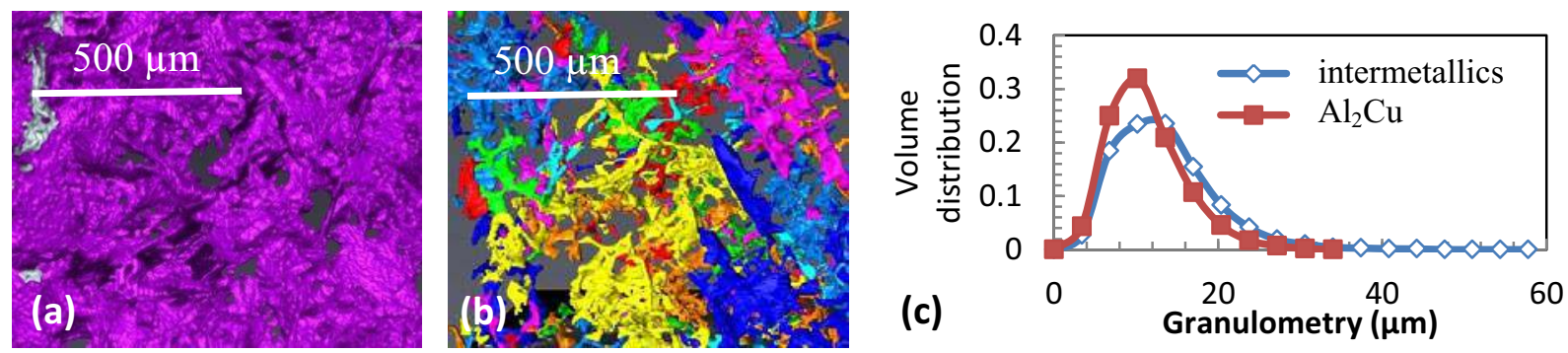

Figure 3. 3D rendering of (a) iron intermetallics. (b) $\mathrm{Al}_{2} \mathrm{Cu}$ phase and (c) their thickness distributions in volume fraction

\subsection{Full field measurements of in-situ tensile tests}

An isotropic element with a 16 voxel edge was used for DVC in a zone of interest of $688 \times 768 \times$ 768 voxels $^{3}$ inside the specimen. 3D displacement field and longitudinal strain field along the loading direction at $198 \mathrm{MPa}$, which is the last step before failure, are shown in Figure 4 (a) and (b). A good correlation is observed between displacement discontinuities and strain localization in the measured field and the cracks. The correlation residual error is found to be, maximum at the cracks locations in Figure 4(c), thus it provides a less arbitrary way to extract the cracks than greyscale thresholding from the tomography image. The correlation between the cracks and pores and hard inclusions can be observed in Figure 4(d). Applying this method to the 6 loading steps, the $3 \mathrm{D}$ cracks are observed to initiate at large pores and microshrinkage cavities and then 
to propagate along the hard inclusions towards the free surface when cracks originate from a subsurface pore.

(a)

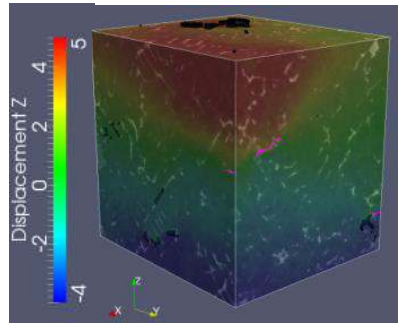

(b)

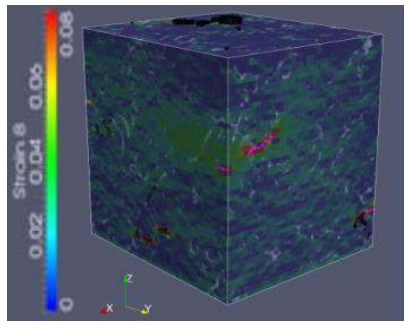

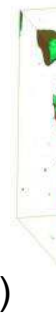

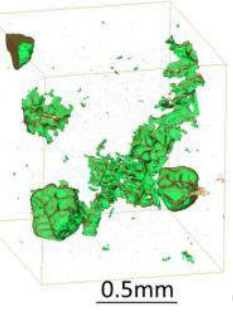

(d)

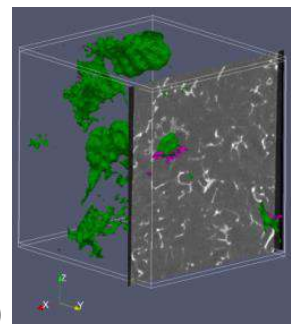

Figure 4. (a) 3D displacement field (in voxels) along loading direction (z-axis) and (b) Ezz strain field with pores shown in grey and cracks shown in purple color; (c) comparison of residual error in yellow and cracks segmented (roughly) in red color; (d) correlation between cracks and pores and hard inclusions.

The strain field along the loading direction $(\varepsilon z z)$ was averaged over the whole volume at each loading step in order to determine the stress-strain curve in Figure 5(a). Compared with the experimental curve of the same material obtained from a conventional test, i.e. with appropriate extensometry measurement on larger specimens, the curve derived from DVC can be considered reliable. This stress-strain curve deduced from DVC is then used for FEM simulation of the porous matrix, and the strain field is shown in Figure 5(b). In the areas where large deformations around pores are observed, a good correlation is observed between the strain field measured from DVC (Figure 4(b)) and that computed from Abaqus; this emphasizes the influence of pores on strain localization under monotonic tensile loading. The displacement field measurement uncertainty [6] was calculated in order to assess the feasibility of DVC for A319 alloy, and DVC was considered reliable as the uncertainty was only 0.218 voxel for an element size of 16 voxels.

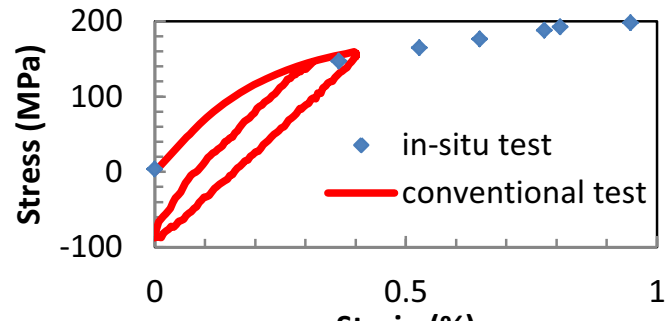

(a)

Strain (\%)

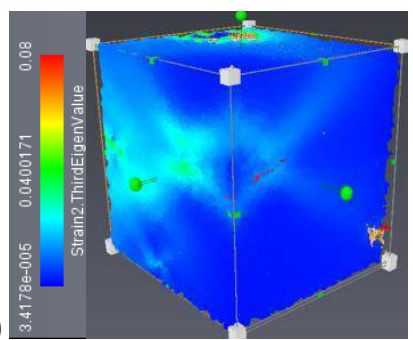

Figure 5. (a) Stress-strain curve, (b) 3D strain field ( $\left.\varepsilon_{z z}\right)$ along the loading direction from FEM simulation with pores shown in yellow color and cracks shown in red color

\section{Conclusions}

In order to study the influence of the microstructure of a cast Al-Si alloy upon its mechanical behaviour, an experimental protocol has been set up and applied using X-ray tomography and digital volume correlation. The most suitable specimens were screened and characterized in 3D to reveal defects and hard inclusions in the interdendritic space with X-ray tomography. The correlation residual error, which is maximum at the cracks locations, constitutes a non-arbitrary way to extract the cracks. Cracks were observed to initiate at large pores and microshrinkage cavities and then to propagate along the hard inclusions towards the free surface. The stressstrain curve derived from DVC was considered reliable by comparison with an experimental curve obtained with conventional extensometry method. In the areas where large deformations 
around pores were observed, a good correlation was observed between the strain field measured from DVC and that computed from FEM using Abaqus. This emphasized the influence of pores on strain localization under monotonic tensile loading. The validated experimental protocol presented here has already been applied to in-situ fatigue tests using synchrotron tomography and a 2D/3D image correlation platform based on C++ newly developed at LML laboratory and designed to process large data volumes in a limited amount of time. Preliminary results are presented in another paper in this conference.

\section{Acknowledgements}

The authors wish to thank the ANR (Agence Nationale de la Recherche) and PSA Peugeot Citroën for funding the study on Al-Si aluminum alloys.

\section{References}

1. Q.G. Wang, D. Apelian, D.A. Lados, "Fatigue behavior of A356-T6 aluminum cast alloys. Part I. Effect of casting defects," Journal of Light Metals, 1 (2001), 73-84.

2. X. Cao and J. Campbell, "The Nucleation of Fe-Rich Phases on oxide films in Al-11.5Si0.4Mg cast alloys," Metallurgical and Materials Transactions A, 34 (7) (2003), 1409-1420.

3. S. Tabibian, E. Charkaluk, A. Constantinescuc, F. Szmytkaa, A. Oudin, "TMF-LCF life assessment of a Lost Foam A319 aluminum alloy," International Journal of Fatigue, 53 (2013), $75-81$.

4. J-Y. Buffière, S. Savelli, P.H. Jouneau, E. Maire, R. Fougères, "Experimental study of porosity and its relation to fatigue mechanisms of model Al-Si7-Mg0.3 cast Al alloys," Materials Science and Engineering A, 316 (2001), 115-126.

5. J. -Y. Buffière, E. Maire, J. Adrien, J. -P. Masse, E. Boller, "In situ experiments with X ray tomography: an attractive tool for experimental mechanics," Experimental Mechanics, 50 (3) (2010), 289-305.

6. N. Limodin, A. El Bartali, L. Wang, J. Lachambre, J-Y. Buffière, E. Charkaluk, “Application of X-ray microtomography to study the influence of the casting microstructure upon the tensile behaviour of an Al-Si alloy," Nuclear Instruments and Methods in Physics Research Section B: Beam Interactions with Materials and Atoms, 324 (2014), 57-62.

7. V. Boulos, V. Fristot, D. Houzet, L. Salvo, P. Lhuissier, "Investigating performance variations of an optimized GPU-ported granulometry algorithm" in : Design and Architectures for Signal and Image Processing (DASIP), Karlsruhe, Germany (2012), 1-6.

8. J. Réthoré, N. Limodin, J-Y. Buffière, F. Hild, W. Ludwig, S. Roux, "Digital volume correlation analyses of synchrotron tomographic images," Journal of Strain Analysis for Engineering Design, 46 (2011), 683-695. 